Journal of

Food and Nutrition

\title{
Conditions for the Appearance and Disappearance of Dislikes of Food in Japa- nese Students
}

\section{Rie Horiuchi ${ }^{1 \star}$, Yuko Maki ${ }^{2}$, Koichi Shirokoshi ${ }^{3}$, Miki Tokunaga ${ }^{4}$, Ram B. Singh ${ }^{5}$, Douglas W. Wilson ${ }^{6,7}$, Harpal S. Buttar ${ }^{8}$ and Toru Takahashi ${ }^{9}$}

${ }^{1}$ Department of Food Sciences and Nutrition, Faculty of Human Environmental Sciences, Mukogawa Women's University; 6-46, Ikebiraki-Cho, Nishinomiya city, Hyogo prefecture 663-8558, Japan

${ }^{2}$ Department of Life and Culture Studies, Sonoda Women's University; 7-29-1 Minamitukaguchi-cho, Amagasaki city, Hyogo prefecture 661-8520, Japan

${ }^{3}$ Department of Early Childhood Care and Education, Faculty of Human Sciences, Osaka University of Human Sciences; 1-4-

1, Syoujyaku Settu city, Osaka prefecture 565-8501, Japan

${ }^{4}$ School of Nutrition and Dietetics, Kanagawa University of Human Service

${ }^{5}$ Halberg Hospital and Research Institute; Civil Lines, Moradabad (UP) 244001, India

${ }^{6}$ School of Medicine, Pharmacy and Health, Durham University; Stockton Road, Durham, DH1 3LE, UK

${ }^{7}$ Centre for Ageing and Dementia Research, Haldane Building, Swansea University; Swansea, SA2 8PP; UK

${ }^{8}$ Department of Pathology \& Laboratory Medicine, Faculty of Medicine, University of Ottawa; Ottawa, ON, Canada K1N 6N5

${ }^{9}$ Department of Food and Nutrition, Faculty of Home Economics, Koriyama Women's University; 3-25-2, Kaisei Koriyama

963-8503, Japan

${ }^{\star}$ Corresponding author: Rie Horiuchi, Department of Food Sciences and Nutrition, Faculty of Human Environmental Sciences, Mukogawa Women’s University; Tel: +81-798-45-3769; Email: mhor9496@mukogawa-u.ac.jp

Received Date: August 09, 2019 Accepted Date: September 20, 2019 Published Date: September 23, 2019

Citation: Rie Horiuchi (2019) Conditions for the Appearance and Disappearance of Dislikes of Food in Japanese Students. J Food Nutr 5: 1-8.

\begin{abstract}
School lunches are a good opportunity for children to learn ideal eating habits for Japanese dishes. On the other hand, leftovers of school lunches might decrease the educational effects of Japanese school lunches. Reducing the occurrences of children's dislikes might facilitate children in learning ideal dietary habits. The purpose of the present study was to evaluate the conditions resulting in the appearance and the disappearance of dislikes. Participants were all female students attending a senior high school in Japan $(n=64)$. Cross-sectional data were used. The most common appearance of dislikes was during elementary school, the second most common appearance was during kindergarten ( $\mathrm{p}<0.001)$. Conditions affecting the appearance of dislikes were the intake of eggs once a day, the intake of confectionary once a day, and the intake of grain twice a day (which would correspond to the intake of a meal without grains or skipping meals) $(\mathrm{p}<0.001)$. The most common reason given for the disappearance of dislikes was "I have a better understanding of the good taste of offensive foods" ( $\mathrm{p}<0.001)$. Thus, elementary school children's dislikes appeared when they ate confectionaries once a day, ate a meal without grain, or skipped meals. Educating children to avoid these habits might help to decrease the appearance of children's dislikes. On the other hand, dislikes might disappear after junior high school due to a greater understanding of offensive foods.
\end{abstract}

Keywords: The appearance of dislikes; The disappearance of dislikes; Female students; Association rule

(C)2019 The Authors. Published by the JScholar under the terms of the Creative Commons Attribution License http://creativecommons.org/licenses/ by $/ 3.0 /$, which permits unrestricted use, provided the original author and source are credited. 
Introduction

School lunches provide children with opportunities to learn the ideal nutritional content and composition of dishes in Japan [1]. Furthermore, eating school lunches could contribute to children's learning the ideal eating habits for Japanese dishes. However, leftovers from school lunches might decrease the educational effects of these lunches [2]. Research has shown that children's dislikes tend to increase when they receive leftovers from school lunches [3]. It follows, then, that decreasing the occurrence of dislikes might create more opportunities for children to learn ideal dietary habits.

There are several methods for decreasing the appearance of food-related dislikes [4]. Managing the conditions under which dislikes appear or disappear is one such method; however, the specific conditions remain obscure [5]. Understanding the conditions leading to the appearance or disappearance of dislikes could suggest an effective method of controlling dislikes in children. The purpose of the present study was to identify these conditions among high school students.

\section{Materials and Methods}

\section{Participants}

A total of 64 female students in the all-female Osaka Kun-Ei Jogakuin Senior High School, located in the school in Setu city, Osaka Prefecture, Japan, participated in this study. The participants included 32 freshmen and 32 sophomores. There are 244 total female students in the freshman class and 259 total female students in the sophomore class. Due to the young age of the participants, we assumed that they could readily recall their childhood diets [4]. The study was conducted in a sports nutrition class that the participants were enrolled in and that did not cover food dislikes. While types and manners of the appearance and disappearance of male students' food dislikes differ from those of female students [6], this study focused on the impacts of dislikes of foods in young women, and male students were not included in this study. Therefore, we selected the senior high school only for girls. No participants dropped out of the study. Most of the participants were from Osaka (67.7\%) and Hyogo (11.3\%) prefectures; other prefectures represented included Aichi, Hiroshima, Kyoto, Nara, and Shiga.

\section{Design and procedures}

This study was cross-sectional, and data were collected using a self-report questionnaire. The questionnaire was administered to students attending Osaka Kun-Ei Jogakuin senior high school on February 2013. We obtained informed consent from all participants. The class did not cover content related to the items of the questionnaires.

\section{Questionnaire}

The questionnaires included 6 question items: "Do you have dislikes?" "When did the appearance of dislikes occur?" "When did the disappearance of dislikes occur?" "Why did the disappearance of dislikes occur?" "Why did the appearance of dislikes occur?" and "How often do you eat grain, potatoes, eggs, fish, meat, yellow vegetables, green vegetables, milk, bean products, seaweed, fruit, confectionery, beverages, and instant food products?" (Table 1). The final item evaluated the frequency of intake of each type of the listed foods (see table 1). Answers of "You hardly eat at all," "You eat once a week," "You eat once a day," and "You eat three times a day" were given scores of 1, 2, 3, and 4, respectively.

Only one reason for the disappearance of dislikes was listed on the questionnaire for participants: "I have a better understanding of how good offensive foods taste"[6]. We also added a free description section. We chose only one item because in a preliminary survey among female college students of the reasons for the disappearance of dislikes, $98 \%$ of the individuals reported: "I have a better understanding of how good offensive foods taste" (Horiuchi et al. unpublished data).

The reasons for the appearance of dislikes were as follows: "I felt ill after eating the food," "I vomited when I ate the food," "I disliked the taste of the food," "I ate the food when I was sick, therefore, I disliked the food," "I disliked the smell of the food," "I had abdominal pain when I ate the food," and "I disliked the appearance of the food" [6]. We also conducted a preliminary among female college students on the reasons for the appearance of dislikes, which indicated that $16 \%$ of participants reported: "I disliked the texture of the food" (Horiuchi et al. unpublished data). We, therefore, added this item to the rest listed above. A free description section was also provided to allow participants to report their answers. 
Table 1. Options and items on the questionnaire

\begin{tabular}{ll}
\hline Items & Options \\
\hline
\end{tabular}

Do you have dislikes?

When did the appearance of dislikes occur? When did the disappearance of dislikes occur?

Why did the disappearance of dislikes occur?

Why did the appearance of dislikes occur?

How often do you eat grain, potatoes, eggs, fish, meat, yellow vegetables, green vegetables, milk, beans products, seaweed, fruit, confectionery, beverages, and instant food products?

\section{Measurement of height and weight}

Body heights and weights were measured with a digital height scale (4D200R, Endou-Densikougyou Co.) and a weight scale (BC-612, Tanita Co.).

\section{Statistics}

The results of the frequency of food intake were presented as means and standard deviations. The remainder of the results were presented as numbers and percentages. Differences in the frequency of food intake between subjects with dislikes and subjects without dislikes were analyzed using the Mann-Whitney $U$ test, while differences in the remaining variables between subjects with and those without dislikes were analyzed using the chi-square test. Differences with $\mathrm{p}<0.05$ were considered significant. Differences in the appearance or disappearance of dislikes at different life stages were analyzed using the chi-square test. We analyzed the conditions for the appearance of dislikes using a statistical method called "association rules" [7], an analysis method used for identifying co-occurring items, such that when one item occurs, a posteriori probability of the occurrence of the other item is high. These probabilities are estimated using three indices: support, confidence and lift indices [8]. In this study, confidence represents the probability that dislikes will occur when children eat food at the associated frequency [8], while lift represents a probability calculated by dividing the probability that dislikes occur when a child eats food at the associated frequency by the probability that dislikes occur at all [8]. Support represents the probability that an item in the condition column and dislikes occur simultaneously. High support, confidence, and lift indicate high reliability that conditions favorable to the appearance of dislikes have arisen [8]. Statistical analysis was performed using SPSS Statistics 20 (IBM Japan ltd., Tokyo, Japan) and R version 3.2.0 (The R Project for Statistical Computing, Vienna, Austria).

This study was reviewed and approved by the Fukuoka Women's University Ethics Committee (No: 2010-08). We obtained the informed consent from the children directly, as it was judged that they could appropriately express their intention to participate.

\section{Results}

\section{Appearance of dislikes}

The percentage of subjects with dislikes was higher than that of subjects without dislikes $(\mathrm{p}<0.05$, Table 2$)$, at $74 \%$ and $26 \%$, respectively (Table 2 ). 
Table 2. The numbers and percentages of subjects with dislikes and subjects without dislikes.

\begin{tabular}{llcc}
\hline & Subjects without dislikes & Subjects with dislikes & $\mathrm{P}^{*}$ \\
\hline Numbers (percentage) & $16(26)$ & $45(74)$ & $<0.01$ \\
\hline
\end{tabular}

Subjects were 61 female students. Sixty-four students participated. Three students did not respond.

* probability calculated using the chi-square test in differences of the number of subjects. The numbers of subjects corresponding to dislikes were shown in the left column. The percentage (count/100 counts) of subjects corresponding to dislikes was shown in parentheses.

The incidence of the appearance of dislikes varied among life stages $(\mathrm{p}<0.001$, Figure 1$)$. The stage with the highest incidence was early an elementary school, followed by a late elementary school (Figure 1).

\section{Disappearance of dislikes}

There were differences in the incidence of the disappearance of dislikes according to life stage ( $p<0.001$, Figure 2 ). The stage with the highest incidence was junior high school (Figure 2).

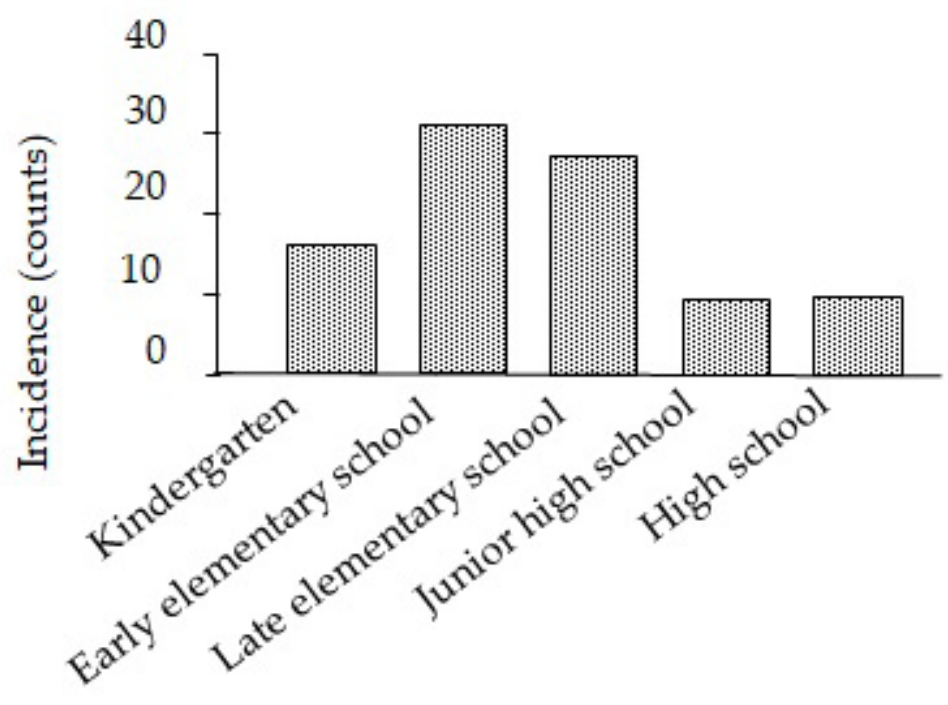

Life stages

Figure 1. Comparison of incidence of the appearance of dislikes according to life stage $(n=64)$.

There was no difference in the reasons for the appearance of dislikes (Table 3, $\mathrm{p}=0.8$ ).

\section{Frequency of food intake}

The frequency of intake of confectioneries in subjects with dislikes was higher than that was that of subjects without dislikes ( $\mathrm{p}=0.04$, Table 4 ). On the other hand, in subjects with dislikes, the frequencies of intake of bean products and fruits were lower than were those of subjects without dislikes $(\mathrm{p}<0.04$, Table 4).
Most subjects reported that the reason for the disappearance of dislikes was "I have a better understanding of how good offensive foods taste" (85\%) (Table 5). 
Table 3.The numbers and percentage in respective reasons of subjects with reasons for the appearance of dislikes

\begin{tabular}{lll}
\hline & $\begin{array}{l}\text { The numbers of } \\
\text { subjects (count/100 counts) }\end{array}$ & $\mathbf{p}^{*}$ \\
\hline I felt ill after eating the food. & $8(36)$ & 0.8 \\
I disliked the taste of the food. & $3(14)$ & $3(14)$ \\
I disliked the texture of the food. & $2(9)$ \\
I disliked the smell of the food. & $2(9)$ \\
I vomited when I ate the food. & $0(0)$ \\
I disliked the appearance of the food. & & $4(18)$ \\
Free descriptive answer & & \\
I had gotten tired of eating the food.
\end{tabular}

Subjects were 22 subjects with dislikes. Forty-five subjects had experienced the appearance of dislikes. Twenty-three participants did not respond.* probability calculated using the chi-square test in differences in the number of subjects among 7 variables. The numbers of subjects corresponding to the reason for the appearance of dislikes were shown in the left column. The percentages (count/100 counts) of subjects were shown in parentheses. Free descriptive answers of 7 existed. Three descriptive answers of them accorded to "I felt ill after eating the food." Accordingly, the 3 answers added in the option of "I felt ill after eating the food". The other answers of them were "I had gotten tired of eating the food."

Table 4. Comparison of the frequency of intake of different foods between subjects with dislikes and those without.

\begin{tabular}{|c|c|c|c|c|c|}
\hline & \multicolumn{2}{|c|}{ Subjects without dislikes } & \multicolumn{2}{|c|}{ Subjects with dislikes } & \multirow{2}{*}{$\mathbf{p}^{*}$} \\
\hline & Mean & SD & Mean & SD & \\
\hline Grain & 5.8 & 0.6 & 5.4 & 0.8 & 0.1 \\
\hline Potatoes & 3.3 & 0.8 & 3.0 & 0.9 & 0.1 \\
\hline Eggs & 3.2 & 1.3 & 3.4 & 1.1 & 0.6 \\
\hline Fish & 3.2 & 0.8 & 3.1 & 0.9 & 0.7 \\
\hline Meat & 4.2 & 1.0 & 4.1 & 1.0 & 0.3 \\
\hline Green vegetables & 4.6 & 1.1 & 4.3 & 0.9 & 0.3 \\
\hline Yellow vegetables & 4.7 & 0.7 & 4.3 & 1.0 & 0.1 \\
\hline Milk & 4.0 & 1.1 & 4.1 & 0.9 & 0.7 \\
\hline${ }^{\mathrm{s} B e a n}$ products & 3.4 & 1.1 & 2.7 & 1.0 & 0.04 \\
\hline Seaweed & 3.5 & 1.0 & 3.2 & 1.1 & 0.2 \\
\hline Fruits & 3.6 & 0.8 & 2.8 & 1.2 & 0.01 \\
\hline Mushroom & 3.2 & 1.0 & 2.7 & 1.1 & 0.08 \\
\hline Oils & 3.2 & 1.2 & 3.7 & 1.3 & 0.2 \\
\hline Confectionaries & 2.8 & 1.0 & 3.6 & 1.1 & 0.01 \\
\hline Beverages & 2.8 & 1.1 & 3.3 & 1.2 & 0.1 \\
\hline Instant food & 2.2 & 1.3 & 2.0 & 1.0 & 0.5 \\
\hline
\end{tabular}

Subjects were 64 female students. All participants responded. Frequencies are presented as means and SD. Intake frequency was evaluated using a questionnaire. Answer options were as follows; Hardly eat at all: 1, Once a week: 2, Three times a week: 3, Once a day: 4 , Twice a day: 5 . \$ Seasonings such as miso and soy sauce were excluded. 
Figure 2. Comparison of incidence of disappearance of dislikes according to life stage $(n=64)$.

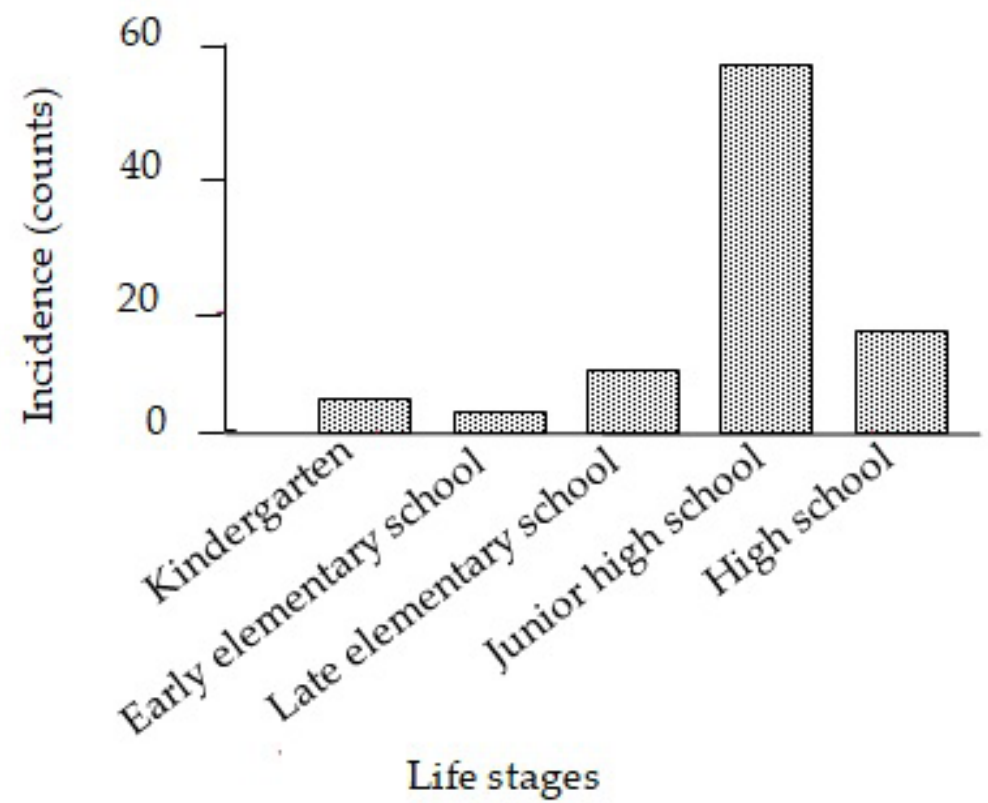

Table 5. The numbers and percentage in respective reasons of subjects with reasons for the disappearance of dislikes.

\begin{tabular}{lcc}
\hline & $\begin{array}{c}\text { The number of Subjects } \\
\text { (count/100 counts) }\end{array}$ & $\mathbf{p}^{*}$ \\
\hline $\begin{array}{l}\text { I have a better understanding of the good taste of offensive foods } \\
\text { Free descriptive answer }\end{array}$ & $28(85)$ & $<0.001$ \\
I came to like the food that previously was offensive. & $3(9)$ \\
Cooking extinguished the dislikes naturally. & $1(3)$ \\
\hline
\end{tabular}

Subjects were 32 female students. Thirty-nine students had experience of disappearance of dislikes. Seven students did not respond. ${ }^{\star}$ probability calculated using the chi-square test in differences in the number of subjects among 3 items. The number of subjects corresponding to each reason for the disappearance of dislikes was shown in the left column. The percentage of subjects corresponding to the reason for the disappearance of dislikes was shown in parentheses. Free descriptive answers included 7 answers. Three descriptive answers of them accorded to "I have a better understanding of the good taste of offensive foods." The other descriptive answers included "I came to like the food that previously was offensive" and "Cooking extinguished the dislikes naturally".

\section{Conditions of the appearance of dislikes}

The conditions leading to the appearance of dislikes were calculated using the association rule, which is expressed using confidence, support, and lift [8]. The two responses with the highest confidence and lift levels were "intake of eggs once a day" and "intake of grain twice a day" (Table 6). The highest level of support was found for "intake of confectionary once a day." Overall, then, the conditions leading to the appearance of dislikes were "intake of eggs once a day," intake of confectionary once a day," and "intake of grain twice a day" (Table 6). 
Table 6. Results of the association rule analysis for the relations between likes and dislikes and frequency of food intake.

\begin{tabular}{lllll}
\hline Condition & Conclusion & Confidence & Support & Lift \\
\hline I eat eggs once a day. & dislikes & 0.90 & 0.31 & 1.23 \\
I eat grain twice a day. & dislikes & 0.86 & 0.21 & 1.18 \\
I eat meat once a day. & dislikes & 0.84 & 0.26 & 1.14 \\
I eat confectionary once a day. & dislikes & 0.83 & 0.33 & 1.13 \\
I eat beverages once a day. & dislikes & 0.82 & 0.31 & 1.12 \\
\hline
\end{tabular}

The law of dislikes affecting the frequency of food intake was analyzed using the association rules. Forty-two subjects without missing values out of 64 females were analyzed. Support represents the probability that an item in the condition column and dislikes (column of conclusion) occur simultaneously. Confidence represents the probability that dislikes will occur when items in condition column occur. Lift represents how many times higher the probability that dislikes occurs when items in condition occur is than the probability that dislikes occurs without the condition.

\section{Physiques of subjects}

The mean age of the subjects was $16.5 \pm 0.4$ (standard deviation: SD) years. The mean height and weight of the subjects were $1.61 \pm 0.06(\mathrm{SD}) \mathrm{m}$ and $54.8 \pm 7.6$ (SD) $\mathrm{kg}$, respectively. A body mass index (BMI, $\mathrm{kg} / \mathrm{m} 2$ ) of less than 18.5 was found in $23.9 \%$ of the subjects, while $75.9 \%$ had a BMI between 18.5 and 23.5 and $4.6 \%$ had a BMI of more than 23.5. The mean BMI of subjects was $20.5 \pm 4.5$ (SD).

\section{Discussion}

\section{Conditions of the appearance of dislikes}

One of the conditions leading to the appearance of dislikes was the intake of grain of twice a day (Table 6). The other conditions related to the appearance of dislikes were the intake of eggs of once a day and the intake of confectionery of once a day (Table 6). An intake of grain only twice a day would suggest that children have eaten a meal without grain or that they have skipped a meal. Therefore, children's dislikes appear under the following conditions during elementary school: intake of eggs once a day, the intake of a meal without grain, meal skipping, or the intake of confectionary once a day.

\section{Conditions of the disappearance of dislikes}

The life stage with the highest incidence of the disappearance of dislikes was junior high school $(\mathrm{p}<0.001$, Figure 2 ). This suggests that we might have the chance to control the disappearance of dislikes around junior high school. The most frequent reason given for the disappearance of dislikes was "I have a better understanding of how good offensive foods taste" $(\mathrm{p}<0.001$, Table 5). Therefore, helping children to understand the good taste of offensive foods around junior high school could help reduce children's dislikes.

\section{Education for preventing the appearance of dislikes}

As noted earlier, the conditions under which children's dislikes appear to relate to the intake of eggs once a day, intake of confectionary once a day, and intake of a meal without grain or skipping meals in the elementary school stage. The mean frequency of intake of confectionery in subjects with dislikes (3.6) was higher than was that among individuals without dislikes (2.8) $(\mathrm{p}=0.02$, Table 4). Thus, parents might educate children on reducing their consumption of confectionary to fewer than three times per week [9] to help decrease the occurrence of children's dislikes.

\section{Education on the disappearance of dislikes}

The results indicated that helping children understand how good offensive foods taste, particularly around junior high school, might help in eliminating children's dislikes. Opportunities to eat offensive foods in school lunches improved understanding of taste [10]. As such, it might be necessary to give children more opportunities to eat offensive foods in school lunches, which might increase their understanding of the taste of these foods [11].

\section{Limitations}

Participants in this study were limited to females at a single high school located in Settu city, Osaka Prefecture. Therefore, the generalizability of the results to all populations should be evaluated with caution. However, the methods employed in this study constitute a fruitful approach to determining the conditions leading to the appearance and disappearance of dislikes. 


\section{Conclusions}

Children's dislikes may appear under the following conditions around the elementary school: an intake of eggs once a day, an intake of confectionary once a day, an intake of a meal without grain, and skipping meals. Educating children to eat less confectionary, to avoid meals without grain, and to avoid skipping meals in elementary school might decrease the occurrence of children's dislikes. On the other hand, dislikes might disappear if children gain an understanding of how good offensive foods can taste after junior high school.

\section{Acknowledgments}

We acknowledge teaching staff, in the senior high school who supported this study. Thanks are especially due to all participants of Osaka Kun-Ei Jogakuin senior high school.

\section{References}

1) Nozue M, Yoshita K, Jun K, Ishihara Y, Taketa Y, et al (2010) Amounts served and consumed of school lunch differed by gender in Japanese elementary schools. Nutr Res Pract 4: 400-404.

2) Horiuchi R, Maki Y, Tokunaga M, Yamamoto Y, Tsukinoki K $\mathrm{T}$, et al. (2018) Influences of school cooking and catering systems on leftover meals and eating behaviors of children. J Food Nutri Diet 2: 115-122.

3) Kawaraya C, Mori H (2009) The dietary habits of junior high school students eating vs. not eating school lunches. Bull.Osaka Shoin Women's Univ 46: 77-90.

4) Matsumoto H, Fukasawa S (2007) Influence of dietary environment and school lunch service on nutritional awareness, eating habits, appreciation of school lunch service and health of junior high school students. Jpn J Home Econ 11: 681-692.

5) Ainuki T, Akamatsu R, Sugimoto N (2013) Longitudinal study of qualitative changes in disliked foods in early childhood. Jpn J Nutr Diet 71: 323-329.

6) Yamamoto T (2017) I like the feelings. In: Fushiki T. Mikaku and Shiko. Domesu Bissers Inc, Tokyo, Japan. 82-111.

7) Séverac F, Sauleau EA, Meyer N, Lefèvre H, Nisand G, et al. (2015) Non-redundant association rules between diseases and medications: an automated method for knowledge base con- struction. BMC Med Inform DecisMak 1-7.

8) Toyoda H (2014) Introduction to Data Mining. Tokyo Shoseki CO, LTD, Tokyo, Japan: 148-183.

9) Kirks BA, Hughes C (1986) Long term behavioral effects of parent involvement in nutrition education. J Nutr Educat 18: 203-206.

10) Sugiyama S, Kitahara T, Miyaoka K, Suzuki M, Ishibashi T, et al. (2016) A. Effects of repeated consumption of rice-fish-vegetable meals on food preferences and eating behaviors of female university students. Jpn J Nutri Foodservice Management 10: 6373.

11) Contento IR, Marnning AD (1992) Research perceptive on school-based nutrition education. J NutrEduc 24: 247-260.

Submit your manuscript to a JScholar journal and benefit from:

ฯ Convenient online submission

ฯ Rigorous peer review

I Immediate publication on acceptance

ब Open access: articles freely available online

9 High visibility within the field

ๆ Better discount for your subsequent articles

Submit your manuscript at http://www.jscholaronline.org/submit-manuscript.php 